Elmar Mittler*

\title{
Monika Cremer zum 75. Geburtstag
}

https://doi.org/10.1515/bfp-2018-0021

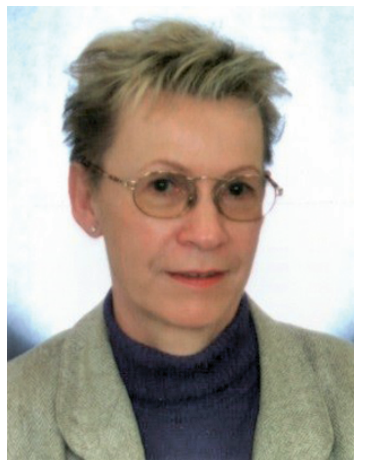

Wir gratulieren Monika Cremer herzlich zum 75. Geburtstag. Seit 1990 redigiert sie engagiert und zuverlässig unsere Zeitschrift. Dabei kommen ihr und uns die vielfältigen Erfahrungen zugute, die sie wie kaum eine andere Kollegin an verschiedenen Bibliotheken und in verschiedenen Positionen sammeln konnte. Ihr Weg führte sie von der Zeitschriftenstelle des Hamburgischen Weltwirtschaftsarchivs $\mathrm{zu}$ den Deutschen Historischen Instituten in Paris (1968-71) und Rom (1971-75) zurück nach Hamburg an das Romanische Seminar der Universität, bis sie 1977 zur Niedersächsischen Staats- und Universitätbibliothek Göttingen wechselte, wo sie bis zu ihrer Pensionierung 2008 in verschiedenen leitenden Positionen wirkte. Überregional wurde sie durch ihre Mitarbeit bei der Kommission Neue Technologien im Verein der Diplombibliothekare an wissenschaftlichen Bibliotheken/Berufsverband Information Bibliothek bekannt, dem sie seit 1980 als Mitglied angehörte. 1989 übernahm sie den Vorsitz, organisierte Fortbildungen und beteiligte sich federführend an Publikationen, die wesentliche Inititalzündungen für die damals noch sehr umstrittene Einführung der EDV und Hilfestellungen für deren konkreten Einsatz in der Bibliotheksarbeit gaben. Diese Aktivitäten erweiterete sie auf das internationale Feld als Secretary and Information Coordinator der IFLA Section on Audiovisual and Multimedia von 1997 bis 2005. Für unsere Zeitschrift aber war es von besonderer Bedeutung, dass sie nach meinem Kommen an die SUB Göttingen das Angebot, die Redaktion zu übernehmen, freudig annahm. Dass es uns möglich ist, ein breites Spektrum bibliotheksbezogener Forschung und Praxis mit Beiträgen aus allen Sparten und aus der ganzen Welt auf hohem Niveau kontinuierlich und rechtzeitig zu publizieren, ist in hohem Maße ihr Verdienst. Es ist so manches Mal in bewundernswerter Weise ihrer nicht immer stabilen Gesundheit abgerungen. Im Namen aller Herausgeber danke ich Monika Cremer für ihre große Leistung und hoffe auf viele weitere Jahre guter Zusammenarbeit.

Mit allen guten Wünschen

Elmar Mittler

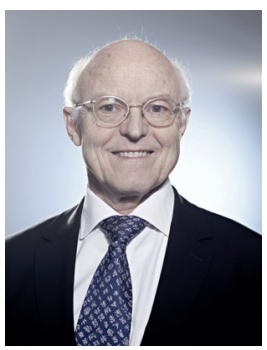

Prof. Dr. h.c. Elmar Mittler c/o Niedersächsische Staats- und Universitätsbibliothek Papendiek 14 D-37073 Göttingen bfp@sub.uni-goettingen.de 